Reference: Rivers, I. (in press). Homophobic bullying in schools. In H. Cowie and C-A Myers (Eds.), Bullying in schools: Intervention and prevention. London: Routledge.

\title{
Homophobic, Biphobic and Transphobic Bullying in Schools
}

\author{
Ian Rivers
}

Research on the bullying and social exclusion of lesbian, gay, bisexual and transgender (LGBT) pupils in schools is now into its third decade. For over twenty years, studies have catalogued the daily torments many LGBTs have faced and continue to face going to school (Rivers, 2011). The wealth of evidence collected has prompted several governments to take action to address the homophobia that has long been apparent in the classrooms, corridors and on the playing fields of our schools. However, despite this wealth of evidence, some politicians, religious leaders and members of the teaching profession remain opposed to the delivery of curricula that acknowledge the diversity that exists within our schools, preferring to remain silent (at best) or overtly discriminate (at worst) against those young people who identify as other than heterosexual, or those who identify as members of the opposite sex.

The existence of homophobic, biphobic and transphobic (HBT) bullying is a mark of shame for many educational systems. There are probably few people reading this chapter who do not recall a peer in their class or year group being bullied mercilessly because of their actual or perceived sexual orientation, or because they were gender atypical:

For almost a year of my school life I spent every break and every dinner break sitting in the back of the ... of the toilet area reading because I knew I was safe there, that I was isolated, and no one would give me any hassle (Rivers, 2011, p. 146).

HBT bullying is a feature of the majority if not all of the educational systems around the World (UNESCO, 2015). In Asia and the Pacific, societal expectations inform the ways in 
which those who do not adhere to cultural expectations are treated by others, and this begins at school:

In many cultures, social order, family honour, and sexual purity provide a longstanding foundation for what is considered to be acceptable behaviour. This includes societal expectations of heterosexual marriage, and the importance of having children to ensure care of elders and the family lineage. Research demonstrates that homophobia, biphobia, transphobia, intersex prejudice, heteronormativity and intolerance characterise peer interactions among many young people in schools of Asia-Pacific (UNESCO, 2015, p. $10)$.

HBT bullying has increasingly been cited as a priority for schools and, as noted earlier, national governments have begun to invest in the delivery of anti-bullying programmes that claim to tackle this form of abuse. However, there remains little independent evidence of the success of the majority of these programmes in terms of reducing bullying directly and, more importantly, whether any reported reduction is cost effective and, ultimately, sustainable (Rivers, 2014).

\section{HBT bullying in schools: The evidence}

Although reference to the bullying of LGB young people appeared in reports published in the 1980s (see Trenchard and Warren, 1984) in the United Kingdom (UK), the first detailed investigation of the nature, correlates and long-term effects of what became known as 'homophobic bullying' was conducted in the early 1990s with a sample of LGB adults recalling their experiences at school (Rivers, 2001). This research demonstrated that homophobic bullying was deliberate and systematic, often perpetrated by groups of peers rather than by individuals. While some participants in this study had overcome their experiences at schools, others had not. Overall 53\% reported that they had thought about 
ending their own lives when they were at school with $40 \%$ attempting suicide once and three quarters of those more than once.

Following on from this early research, two further surveys sponsored by the UK charity Stonewall (Hunt and Jensen, 2007; Guasp, 2012) indicated that while homophobic bullying had decreased among their samples from $65 \%$ in 2007 to $55 \%$ in 2012 , not enough was being done to combat it. In their 2012 survey, 58\% of those who had been bullied were subjected to verbal abuse, $46 \%$ were the victims of gossip and $33 \%$ said they had received intimidating looks. Others reported being ignored (31\%), being harassed via technology ('cyberbullying' $23 \%$ ), physically hurt by others (16\%), having property vandalised (11\%), receiving hurtful telephone and text messages $(9 \%)$, death threats $(6 \%)$, being threatened with a weapon (3\%) and being sexual assaulted (3\%).

In the United States (US), GLSEN (Gay, Lesbian and Straight Education Network) has undertaken biennial surveys (National School Climate Survey) of bullying and victimisation of LGBT young people since 1999. GLSEN's data have shown that, over the years, while there has been a significant decline in overt verbal harassment experienced by LGBT young people, rates of physical assault have remained stable. In terms of bullying and harassment arising from gender expression, once again GLSEN has shown a consistent decline in reports of overt verbal harassment but there has not been a concomitant decline in reported rates of physical assault.

One of the most detailed surveys of HBT bullying was undertaken between 2001 and 2002 by the California Safe School Coalition with researchers from the University of California-Davis. They surveyed 237,544 young people in grades 7-11 (ages 12 to 17 years) who were asked about their experiences of all forms of bullying. Overall they found that $7.5 \%$ of young people reported having been victims of HBT bullying and that two out of every three LGBT young people were bullied because of their actual or perceived sexual 
orientation (California Safe Schools Coalition and 4-H Centre for Youth Development, University of California, Davis, 2004). Additionally, those who were bullied because of their actual or perceived sexual orientation were more likely to receive lower grades at school (grade ' $\mathrm{C}$ ' or below) when compared to those who were not bullied (24\% versus $17 \%)$. They were also more likely to miss school because they reported feeling unsafe ( $27 \%$ versus $7 \%$ ). Additionally, they were twice as likely to engage in health risk behaviours and were nearly six times more likely to be threatened or hurt by someone carrying a weapon $(28 \%$ versus $5 \%)$. They were also four times more likely to carry a weapon themselves (19\% versus 5\%).

In terms of trans young people's experiences of bullying, data collected by the charity gendered intelligence (n.d.) suggests it begins in primary school and can continue into college and university:

Primary school; always got told by the older girls that I was in the wrong toilet. To the extent of physical bullying and being scared of being in the toilets. But obviously 'cause I'd been told from birth I'm a little girl, using those toilets. Going in to those toilets and actually missing classes 'cause I was hiding... in the cubicle 'cause I'd heard that the older girls or girls in my class were in the toilets chatting... for about 20 minutes or something, not caring - 'cause they're in like year 6 -that they're missing their class, but I was sitting there in year 4 thinking 'oh my god my teachers going to tell me off again... because I'm like 'oh well I can't leave this cubicle' (p. 8).

For some trans youth the term 'bullying' does not convey adequately the violence they have experienced at the hands of peers which would, in any other situation, result in police action: 
I'd just like to record an objection to a word, 'bullying'. Because I think it continues to entrench the state of denial that schools and the government are in about what happens in schools. Which, in any other situation, would be called 'abuse', or 'harassment', and would be a criminal offence, which the police would deal with. But because it's in schools, it's just 'oh it's just kids being kids' and they need to get serious and start actually recognising when abusive crimes are happening and erm, you should have the same protection there as you would in the home (p. 29).

There has been criticism of research on bullying and harassment and its mental health correlates due to its focus on negative experiences rather than taking a holistic view of young people's development (see Savin-Williams, 2005). Additionally, some researchers have argued that we need a much more nuanced understanding of young people's discourses and the dynamics of their relationships with others to determine whether phrases such as "that's so gay" are in fact homophobic (see, for example, McCormack, 2013). For some the argument is that the phrase "that's so gay" has become part of the young people's discourse and in environments that are supportive it is something other than homophobic; there is no intent to marginalise or discriminate, rather there is a desire to bond or to identify with the speaker. Thus, in a school where there are high levels of intolerance towards LGBTs the intent behind a comment such as "that's so gay" may be entirely different from a school where there is support for LGBT pupils and staff. Of course, it should be noted that this argument does not apply to the use of all LGBT-themed epithets - many of which are clear in their intent to cause harm or otherwise denigrate the target (see Thurlow, 2001).

\section{Mental health correlates of HBT bullying}


According to Hatzenbuehler (2011) the social spaces and political environments LGBT young people occupy play a significant part in their mental health and well-being. In the absence of visible support mechanisms such as LGBT groups, public figures and clubs increased levels of emotional disturbance and suicide ideation appear. Using pooled data from the 2005 and 2007 Youth Risk Behavior Surveillance (YRBS) surveys (N=55,559, aged 13-18 years), Hatzenbuehler et al. (2014) found that suicide ideation among LGB young people was lower in counties and cities where sexual minority students reported feeling more protected and less isolated (e.g. they had identified safe spaces to go to, or their schools had a Gay-Straight Alliances). In developing his Minority Stress Theory, Meyer (2003) argued that invisibility and experiences of discrimination - which he described in terms of proximal factors (personal fear of rejection, further isolation or experiences of prejudice) and distal factors (societal prejudice and discrimination) - influence well-being and, ultimately, impact upon proactive engagement with society.

To date, numerous studies suggest that there are long-term and life-threatening effects associated with HBT bullying (see, for example, Poteat, Rivers and Scheer, 2016). In addition to the reports of suicide ideation reported in Rivers' (2001) study, in its 2012 study, Stonewall reported that $41 \%$ of LGB respondents had deliberately self-harmed as a result of homophobic bullying (biphobic and transphobic bullying were not considered). GLSEN's (2011) report indicated that high rates of depression and low-esteem were correlated with HBT bullying for the LGBT young people who participated in its survey. Additionally, in California, $55 \%$ of those who were bullied because of their actual or perceived sexual orientation reported that they had experienced depression for at least two weeks over the last 12 months (compared to $23 \%$ among peers who were not bullied). Over two-fifths (45\%) had seriously considered suicide (compared to $14 \%$ among peers who had not been bullied at school), and $35 \%$ had made a suicide plan (compared to $9 \%$ of non-bullied peers, California 
Safe Schools Coalition and 4-H Centre for Youth Development, University of California, Davis, 2004). However, Rivers (2011) reported that, when compared to heterosexual and LGB adults who were bullied at school for other reasons, those who experienced HBT bullying did not differ significantly in terms of rates of depression or anxiety. However, among 13-16 year olds, Rivers and Noret (2008) reported that those who were attracted to members same-sex $(\mathrm{N}=53)$ scored higher on measures of negative affect when compared to a group of matched controls who were attracted to members of the opposite-sex. Overall, this research suggests that there are both acute/immediate and chronic/long-term correlates of HBT bullying. Both have repercussions for schools and require appropriate interventions that address the mental health distress caused by bullying as well as the behaviour it entails.

\section{Why does HBT bullying exist?}

Ultimately HBT bullying exists because many cultures condemn homosexuality and bisexuality, or perceive people who are trans to be being deviant or dangerous. This was clearly demonstrated in recent legislation introduced in the US to ban trans people from using gender appropriate lavatories. The hysteria associated with fears of assault or voyeurism has been translated into prohibitive legislation for elementary and secondary schools, colleges and universities. For example, the now infamous House Bill 2 (HB2) introduced in North Carolina states that:

Local boards of education shall require every multiple occupancy bathroom or changing facility that is designated for student use to be designated for and used only by students based on their biological sex (General Assembly of North Carolina, 2016 pp 1-2).

Within this particularly pernicious piece of legislation, biological sex refers to, "the physical condition of being male or female, which is stated on a person's birth certificate." For many 
people, such a legislative bill may seem entirely appropriate and the bill contains an exemption allowing for the provision of a single occupancy bathroom of changing facility, "that has been temporarily designated for use by that person's biological sex." However, it is the inference and meaning underpinning the use of the term "biological sex" and the failure of North Carolina's legislature to consider the needs of minorities, preferring to use language that promotes assumptions and beliefs about deviation form biological 'norms'. This has resulted in a number of heterosexual men entering women's public restrooms claiming that they believed a trans person was using the facility illegally.

In order to understand why HBT bullying or, indeed, any form of bullying exists, it is necessary to understand the psychological processes that underpin the decision to bully or intimidate another. Figure 1 provides a graphic representation of a five-stage model of

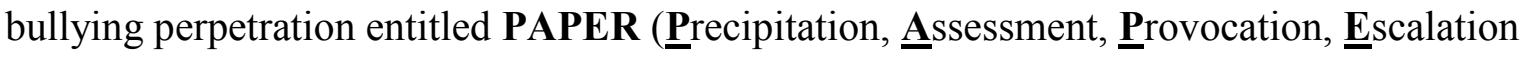

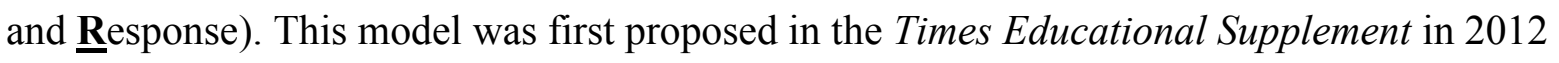
(see Rivers, 2012). It builds upon research drawn from social and developmental psychology and proposes that there are both moderating and mediating factors that can impact upon the decision whether a person bullies another (moderators), or the severity of that behaviour if enacted (mediators).

\section{INSERT FIGURE 1 ABOUT HERE}

The starting point (Precipitation) begins with an assumption or belief about a person or group of people. In his ground-breaking text, The Nature of Prejudice, Gordon W. Allport (1954) demonstrated how assumptions or beliefs, many of which are untrue, influence the prejudices we have against other groups in Society. Beliefs that certain ethnic or cultural groups of "smelly" or "sly" and "tricky" underpin the ways in which we engage with 
members of those communities: when something goes wrong (the catalyst) they are to blame or when something goes right, they have had an unfair advantage or have been prioritised above others. Consequently, they do not deserve praise, reward or, as history has shown, equality.

The allocation of blame resulting from an unfavourable outcome constitutes Stage 2 of the model (ㅅssessment). Here expectations of success or failure are moderated by the outcome. If the outcome is favourable to the minority then Provocation (Stage 3 ) is likely to follow together with emotional escalation. If the outcome is favourable to the majority, then the likelihood of emotional escalation subsides (at least on the part of the potential perpetrator). In terms of bullying behaviour, Galvan et al.'s (2007) study of risk taking behaviour provides useful support for Stage 3 of the PAPER model. This research suggests that, in terms of frontal cortex development, many young people are unable to engage a socalled emotional "braking system" and are, therefore, unable to down-regulate negative reactions to events, resulting in faulty logic and a poor assessment of a given situation. In principle, it seems that the ability to stem negative emotional reactions and challenge those faulty beliefs or assumptions is the key to tackling bullying and especially bullying related to prejudice.

Where the outcome leads to a strong negative emotional reaction, Escalation follows. At this stage, two factors come into play - status and proximity. How perpetrators view themselves relative to the target of their aggression is very important. Violence becomes a means to sustain or enhance personal status within the school-yard hierarchy. If that status cannot be sustained or enhanced then the repercussions may be less severe for the target. Similarly the proximity of the target (same class, same year group, sibling, friend, team mate) may also play a role in the decision to perpetrate bullying. Tajfel (1972) argued that an individual's identity with a particular group of peers (social identity) is related to the 
emotional and evaluative significance membership of that group offers. Through membership of that social group, a person's status within the social hierarchy is determined. Self-worth thus becomes inextricably linked to the way in which one person or group is perceived relative to another person or group. Once again, cognition and motivation are central to understanding why discrimination occurs:

It is cognitive insofar as the categorization process leads the subjects to overestimate intergroup differences and to underestimate ingroup differences. It is motivational insofar as what motivates discrimination is the need for selfesteem and self-respect (Deschamps and Devos, 1998, p. 6).

From the perspective of the perpetrator, a positive assessment of personal status relative to that of the target, and a desire to create distance (in terms of identity) from that target creates both a sense of entitlement to discriminate together with a desire and a need to take action to underscore those differences (Stage 5, Response). The acceptability of discriminatory actions may be based upon those social and cultural factors described in UNESCO’s (2015) report (i.e. social order, family honour, sexual purity and societal expectations of heterosexual marriage and having children to care for elders and the family lineage). It can also be the result of the sanitisation of language (describing behaviour as justifiable punishment rather than unjustified aggression) and the use of expedient historical examples to justify behaviour (e.g. condemnation of particular groups from history or significant cultural or religious texts, see Bandura, 1999; Wiens and Dempsey, 2009).

Of course as society changes and there is greater acceptance of LGBT people, so there should be a concomitant decline in HBT bullying, particularly among young people. Indeed, this argument supports the evidence presented by Savin-Williams (2005) and, to a degree, by McCormack (2013). However, as we have seen, there can also be a conservative challenge to those changes which can result in an escalation in violent action either by individuals or by 
groups. Engaging young people in discussions relating to acts of violence perpetrated against LGBT people is becoming increasingly important. Indeed, the absence of any discussion in the classroom allows misinformation and prejudice to take hold. Teachers ultimately have to be able to talk with confidence about the reasons why some groups are opposed to LGBT equality, and to be able to talk openly and objectively about the different views that people hold and why they hold them.

\section{What works in challenging HBT bullying?}

In 2014 Public Health England commissioned a rapid topic overview of research and interventions associated with homophobic and transphobic bullying (see Rivers, 2014). The resulting report identified a number of interventions, including curriculum-based programmes that were promising in terms of the impact upon rates of bullying. Many of these intervention programmes involved the training of teachers on equality and diversity issues and the use of historical examples to demonstrate to young people the contribution LGBT people have made and continue to make in society. One key intervention that showed a significant long-term impact upon rates of sexual and HBT bullying was a curriculum-based intervention called Second Step ${ }^{\odot}$ which focuses on social-emotional learning and encouraged young people in school to understand the impact of HBT bullying collectively (Committee for Children, 2008). Among 6th and 7th grade school students, Espelage, Low, Polanin and Brown (2015) found that there was a reduction in homophobic name-calling of 56\% two years following the introduction of the program for middle schools. The program included sessions on social emotional skills development (i.e. empathy, assertive communication skills, emotional regulation and problem solving skills). With young people in $6^{\text {th }}$ grade, sessions also covered issues such as recognising bullying and bystander intervention. For those in $7^{\text {th }}$ grade, sessions included advice on responding to bullying, cyberbullying and sexual harassment 
(with a reported reduction of $39 \%$ after two years). Additionally, there was a $42 \%$ reduction in physical violence within the first year (Espelage, Low, Polanin and Brown, 2013).

There are three important features of Second Step ${ }^{\odot}$ that explain its success. Firstly, it breaks down those social identity barriers that promote bullying, teaching empathy and understanding. Second, it promotes emotional regulation and, with an eye to Galvan et al.'s (2007) findings, provides potential perpetrators with an opportunity to 'engage' at all important emotional breaking system. Finally, it promotes communication skills and equips young people with the language necessary to challenge bullying when they encounter it. Comparable with Espelage et al. (2013, 2015), Richards, Rivers and Akhurst (2008) noted that following a nine-week positive psychology intervention in one school that included teaching communication skills, rates of bullying declined and self-reports of well-being improved among 11-year olds.

\section{Summary}

Despite evidence that, for some LGBT young people, school experiences have improved immensely, for others HBT bullying remains a problem. Since those very early studies conducted in the 1990s, there has been significant legislative change, and a commitment by governments to make schools, colleges and universities safe for all young people regardless of their sexual orientation or gender identity. Issues such as marriage equality have proven divisive and the conservative backlash has, unfortunately, impacted upon schools directly. HB2 is one such example. However, LGBT young people are coming out earlier than before and primary/elementary schools are increasingly reporting that they actively support the trans students in their care. While there will always be challenges to LGBT equality, one key lesson that must guide our thinking and practice now and in the future has to be a recognition of the fact that what we teach today will, ultimately, influence the actions of tomorrow. 
Figure 1: Five Stage Model of Bullying Perpetration (PAPER)

Stage 1

Precipitation

Stage 2 Assessment (Moderator)

Stage 3

Provocation

Stage 4 Escalation (Mediator)
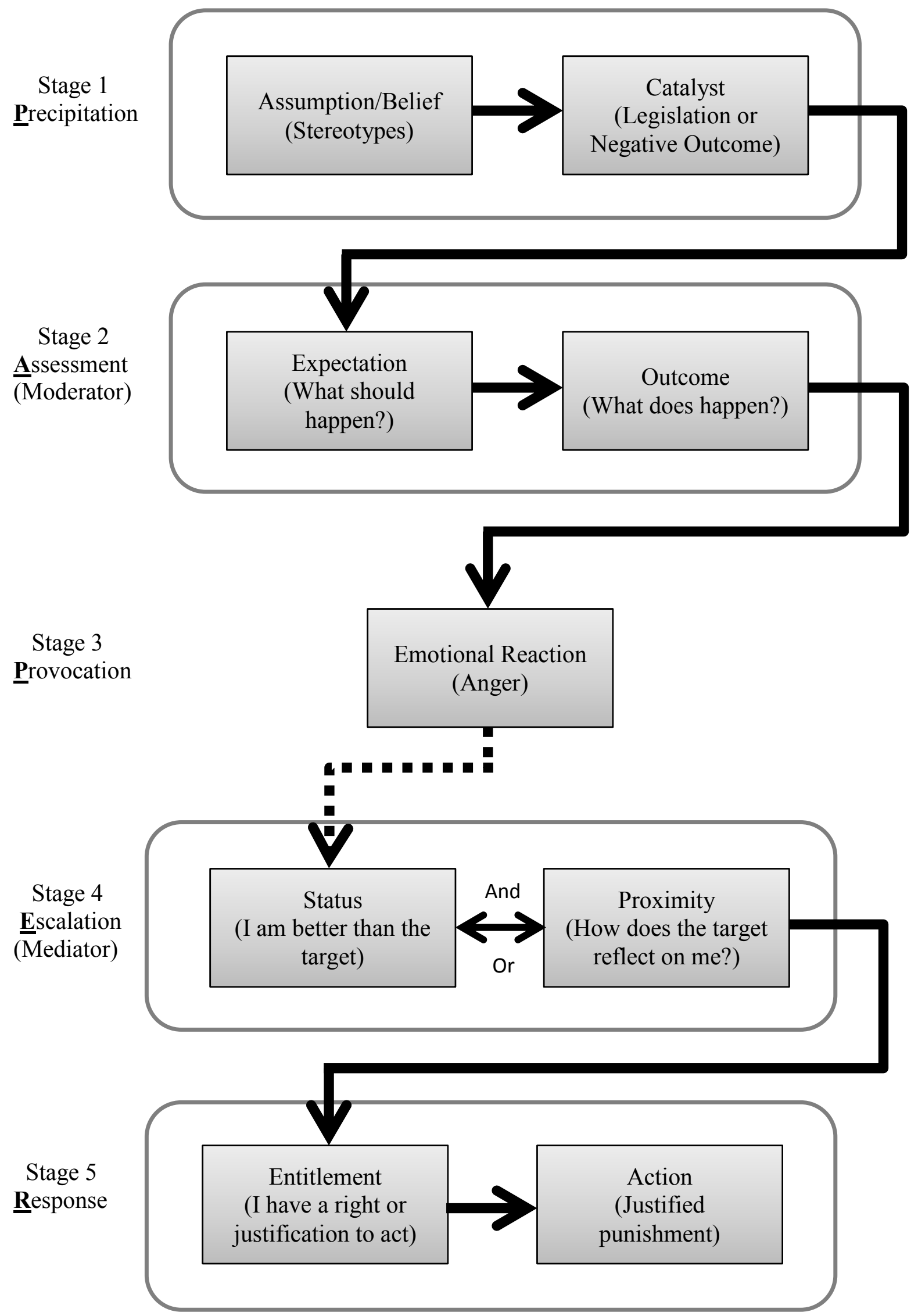


\section{References}

Allport, G.W. 1954. The nature of prejudice. Reading, MA: Addison-Wesley.

Bandura, A. 1999. Moral disengagement in the perpetration of inhumanties. Personality and Social Psychology Review, 3 (3), 193-209.

California Safe Schools Coalition and 4-H Centre for Youth Development, University of California, Davis. 2004. Safe place to learn: Consequences of harassment based on actual or perceived sexual orientation and gender non-conformity and step for making schools safer. San Francisco: California Safe Schools Coalition and 4-H Centre for Youth Development, University of California, Davis.

Committee for Children. 2008. Second step: Student success through prevention program. Seattle, WA: Committee for Children.

Deschamps, J-C. and Devos, T. 1998. Regarding the relationship between social identity and personal identity. In: S. Worchel, J.F. Morales, D. Pàez and J-C Deschamps, eds. Social identity: International perspectives. London: Sage, 1-12.

Espelage, D. L., Low, S., Polanin, J., \& Brown, E. 2013. The impact of a middle-school program to reduce aggression, victimization, and sexual violence. Journal of Adolescent Health, 53 (2), 180-186.

Espelage, D. L., Low, S., Polanin, J. R., \& Brown, E. C. 2015. Clinical trial of Second Step ${ }^{\odot}$ middle-school program: Impact on aggression and victimization. Journal of Applied Developmental Psychology, 37 (1), 52-63.

Galvan, A., Hare, T. A., Voss, H., Glover, G. and Casey, B. J. 2007. Risk-taking and the adolescent brain: Who is at risk? Developmental Science, 10 (2), F8-F14.

genderedintelligence, n.d. Issues of bullying around trans and gender variant students in schools, colleges and universities. Available at: $<$ http://cdn0.genderedintelligence.co.uk /2012/11/17/17-43-56 trans_youth_bullying_report1108.pdf $>$ [Accessed 27 July, 2016]. 
GLSEN. 2011. The 2011 national school climate survey: The experiences of lesbian, gay, bisexual, and transgender youth in our nation's schools. New York: GLSEN.

General Assembly of North Carolina. 2016. House Bill 2. Available at:

$<$ http://www.ncleg.net/Sessions/2015E2/Bills/House/PDF/H2v4.pdf $>$ [Accessed 26 July, 2016].

Guasp, A . 2012. The school report: The experiences of gay young people in Britain's schools in 2012. London: Stonewall.

Hatzenbuehler, M. L. 2011. The social environment and suicide attempts in a populationbased sample of LGB youth. Pediatrics, 127 (5), 896-903.

Haztenbuehler, M. L., Birkett, M., Wagenen, A. van, and Meyer, I. H. 2014. Protective school climate and reduced risk for suicide ideation in sexual minority youths. American Journal of Public Health, 104 (2), 279-286.

Hunt, R. and Jensen, J. 2007. The school report: The experiences of gay young people in Britain's schools. London: Stonewall.

McCormack, M. 2013. Mapping the boundaries of homophobic language in bullying. In: I. Rivers and N. Duncan, eds. Bullying: Experiences and discourses of sexuality and gender. London: Routledge, 91-104.

Meyer, I. H. 2003. Prejudice, social stress, and mental health in lesbian, gay, and bisexual populations: Conceptual issues and research evidence. Psychological Bulletin, 129 (5), 674-697.

Poteat, V. P., Rivers, I. and Scheer, J. R. 2016. Unique mental health concerns, LGBTQ youth. In: M.K. Holt \& A.E. Grills, eds. Critical issues in school-based mental health. New York: Routledge, 105-117. 
Richards, A., Rivers, I. and Akhurst, J. 2008. A positive psychology approach to tackling bullying in secondary schools: A comparative evaluation. Educational and Child Psychology, 25 (2), 72-81.

Rivers, I. 2001. The bullying of sexual minorities at school: Its nature and long-term correlates. Educational and Child Psychology, 18 (1), 33-46.

Rivers, I. 2014. Homophobic and transphobic bullying: Rapid topic overview. London: Public Health England.

Rivers, I. 2011. Homophobic bullying: Research and theoretical perspectives. New York: Oxford University Press.

Rivers, I. 2012. Bully and victims: Busting the myths. Times Educational Supplement, TESpro, 29 June, 8-9.

Rivers, I. and Noret, N. 2008. Well-being among same-sex and opposite sex attracted youth at school. School Psychology Review, 37 (2), 174-187.

UNESCO, 2015. From insult to inclusion: Asia-Pacific report on school bullying, violence, and discrimination on the basis of sexual orientation and gender identity. UNESCO: Paris and Bangkok. Available at: $<$ http://unesdoc.unesco.org/images/0023/002354/235414e.pdf. [Accessed 29 June, 2016].

Savin-Williams, R.C. 2005. The new gay teenager. Cambridge, MA: Harvard University Press.

Tajfel, H. 1972. La catégorisation social. In: S. Moscovici, ed. Introduction à la psychologie sociale. Paris: Larousse, (Vol. 1) 272-302.

Trenchard, L. and Warren, H. 1984. Something to tell you. London: London Gay Teenage Group. 
Thurlow, C. 2001. Naming the "outside within": Homophobic pejorative and the verbal abuse of LGB high-school pupils. Journal of Adolescence, 24 (1), 25-38.

Wiens, B.A. and Dempsey, A. 2009. Bystander involvement in per victimization: The value of looking beyond aggressors and victims. Journal of School Violence, 8 (3), 206-215.

\section{Biographical Information}

Ian Rivers is Professor of Education for Social Change at the University of Strathclyde, Glasgow. He is a developmental and health psychologist and was previously Professor of Human Development at Brunel University London. Ian is a fellow of the American Psychological Association, the British Psychological Society and the Academy of Social Sciences. He is the author of Homophobic Bullying: Research and Theoretical Perspectives (2011, Oxford University Press) which has now been translated in Italian (2015, Il Saggiatore). He is also co-author (with Sheri Bauman) of Mental Health in the Digital Age (2015, Palgrave). Ian is a past recipient of the British Psychological Society's Award for Promoting Equality of Opportunity in the United Kingdom. 